\title{
Ganancia de peso en novillos tratados con un compuesto inyectable de minerales, vitaminas y proteínas
}

\author{
Ríos, E.E. ; Maldonado, P. ${ }^{2}$; Bogado, E.F.; Chileski, G. ${ }^{3}$ \\ ${ }^{1}$ Cátedra Clínica de Grandes Animales, ${ }^{2}$ Cátedra Teriogenología, ${ }^{3}$ Hospital de Clínicas, Facultad de Ciencias \\ Veterinarias, Universidad Nacional del Nordeste, Sargento Cabral 2139, Corrientes (3400), Argentina. \\ Tel/fax 0379-4425753. E-mail: hospital@vet.unne.edu.ar.
}

\begin{abstract}
Resumen
Ríos, E.E.; Maldonado, P.; Bogado, E.F.; Chileski, G.: Ganancia de peso en novillos tratados con un compuesto inyectable de minerales, vitaminas y proteínas. Rev. vet. 24: 1, 56-59, 2013. Las pasturas naturales del nordeste argentino adolecen de deficiencias nutricionales estacionales. El objetivo del ensayo fue verificar los efectos de un compuesto inyectable de minerales, vitaminas y proteínas en novillos Braford de 18 meses de edad (160-200 kg de peso). Se conformaron 3 lotes de 10 animales cada uno. El lote 1 recibió 3 aplicaciones de $10 \mathrm{ml}$ del compuesto vía SC cada 22 días y el lote 2 igual dosis cada 32 días. El lote 3 operó como testigo. Al cabo de 96 días se registraron ganancias de peso de 53,9 $\mathrm{kg}$ (lote 1), 44,8 kg (lote 2 ) y $36,4 \mathrm{~kg}$ (lote 3 ), sin registrarse efectos secundarios adversos. El compuesto ensayado reveló mayor eficacia a la dosis de $10 \mathrm{ml}$ cada 22 días.
\end{abstract}

Palabras clave: novillo, minerales, vitaminas, proteínas, ganancia de peso.

\begin{abstract}
Ríos, E.E.; Maldonado, P.; Bogado, E.F.; Chileski, G.: Weight gain in steers treated with an injectable commercial formulation with minerals, vitamins and proteins. Rev. vet. 24: 1, 56-59, 2013. Natural pastures from northeastern Argentina reveal seasonal nutritional deficiencies. The objective of the trial was to verify the effects of an injectable commercial formulation consisted of minerals, vitamins and proteins, in 18 months old Braford steers (160-200 kg liveweight). Three groups of 10 animals each were submitted to the assay. Group 1 received 3 applications of $10 \mathrm{ml} \mathrm{SC}$ every 22 days, and group 2 the same dose every 32 days. Group 3 was used as a control. After 96 days weight gains of $53.9 \mathrm{~kg}$ (group 1), $44.8 \mathrm{~kg}$ (group 2) and $36.4 \mathrm{~kg}$ (group 3) were registered, without adverse effects. The assayed commercial formulation was more effective at a dose of $10 \mathrm{ml}$ every 22 days.
\end{abstract}

Key words: steer, minerals, vitamins, proteins, liveweight gain.

\section{INTRODUCCIÓN}

La deficiencia nutricional de las pasturas naturales es una de las principales limitantes para el desarrollo de la ganadería del nordeste argentino $^{8}$. En la zona, las proteínas y minerales contenidos en las pasturas revelan deficiencias estacionales, resultando más bajas en invierno. Las deficiencias más notorias serían las de $\mathrm{P}$ y $\mathrm{Na}$, seguidas por las de $\mathrm{Cu}^{5}$.

El objetivo del presente ensayo fue evaluar la efectividad de un compuesto inyectable de minerales, vitaminas y proteínas concebido para generar mayores ganancias de peso en bovinos de cría mantenidos sobre pasturas naturales.

En la composición del producto investigado figuran los aminoácidos lisina y metionina, ambos partícipes en la síntesis de proteínas del organismo (tejido muscu-

Recibido: 4 febrero 2013 / Aceptado: 14 mayo 2013 lar, colágeno, enzimas). Además, la lisina interviene en la absorción de calcio y producción de hormonas y anticuerpos, en tanto que la metionina actúa como lipotrópico y es un poderoso antioxidante. En cuanto a los minerales, el calcio es el principal integrante de los tejidos duros, excitabilidad neuromuscular, coagulación de la sangre, equilibrio acidobase y activación de enzimas. El fósforo, presente en huesos y secreciones, participa en la regulación del $\mathrm{pH}$, almacenamiento de energía, fosforilación de monosacáridos y desarrollo de la flora ruminal. El potasio refuerza la regulación acidobásica, osmolalidad del medio interno y polarización de membranas. El hierro es el principal medio de transporte y almacenaje de oxígeno, integra diversas enzimas, especialmente en cadena respiratoria. El magnesio participa en la excitabilidad neuromuscular, opera como cofactor enzimático y existe en tejidos duros y secreciones. El manganeso es necesario para la síntesis de huesos, glucoproteínas y mucopolisacáridos, además de favorecer 
el desarrollo genital y el funcionamiento muscular. El cobalto actúa como coenzima de sistemas promotores del crecimiento, fertilidad, hematopoyesis, consolidación osteomuscular y otras acciones ${ }^{10}$.

\section{MATERIAL Y MÉTODOS}

Se utilizaron 30 novillos Braford de $18 \pm 2$ meses de edad, recría de rodeo general, de aproximadamente 160 a $200 \mathrm{~kg}$ de peso vivo, identificados con caravanas de trazabilidad. Los animales fueron mantenidos en un establecimiento ganadero situado en el Departamento San Cosme (Provincia de Corrientes, Argentina). Para la experiencia se dispuso de 96 ha de campo con pastura natural y montes, corral con tres subdivisiones, toril, manga con casilla de operaciones, cepo, balanza y cargadero. Durante el desarrollo del ensayo se registraron lluvias regulares que favorecieron un buen rebrote de los pastos, por lo cual el ganado dispuso en todo momento de suficiente oferta forrajera.

Con el objeto de conformar tres lotes, los animales fueron pesados 48 horas antes del inicio de la prueba. A los tres novillos de mayor peso se le fueron adicionando sujetos experimentales con pesos decrecientes hasta completar diez animales por lote, garantizando una distribución lo más uniforme posible al inicio de la experiencia (día cero: 6 de febrero de 2012). Luego, el pesaje individual de todos los animales experimentales se realizó en tres oportunidades, a los días 32 (9 de marzo), 64 (10 de abril) y 96 (12 de mayo). Todos los novillos fueron desparasitados y se les efectuó control de eficacia del antiparasitario aplicado, antes de su incorporación a los lotes. En cada pesaje se efectuaron exámenes clínicos para evaluar el estado de salud de los animales.

El compuesto inyectable ensayado contenía, cada $100 \mathrm{ml}$ : proteínas totales $(1,056 \mathrm{~g})$, fósforo $(1,108 \mathrm{~g})$, calcio $(0,008 \mathrm{~g})$, potasio $(0,041 \mathrm{~g})$, magnesio $(0,01 \mathrm{~g})$, hierro $(2,5 \mathrm{mg})$, manganeso $(0,25 \mathrm{mg})$, cobalto $(0,06$ $\mathrm{mg})$, lisina $(0,54 \mathrm{~g})$ y metionina $(0,126 \mathrm{~g})$. Los animales del lote 1 recibieron vía $\mathrm{SC}$ dosis de $10 \mathrm{ml}$ por cabeza, cada 22 días, durante 96 días (cuatro aplicaciones totales). Los animales del lote 2 recibieron vía SC dosis de $10 \mathrm{ml}$ por cabeza, cada 32 días, durante 96 días (tres aplicaciones totales). El lote 3 operó como testigo sin tratamiento.

\section{RESULTADOS Y DISCUSIÓN}

Las Tablas 1, 2 y 3 muestran, para cada lote respectivamente, los pesos iniciales y la evolución del peso vivo registrado mensualmente en los novillos, así como las ganancias diarias de peso (gramos) y la ganancia final (kilogramos). Dado que el promedio de incremento total de peso corporal para el lote 1 fue de $53,9 \mathrm{~kg}$ mientras que para el lote 2 fue de $44,8 \mathrm{~kg}$, resultó evidente la ventaja de aplicar el compuesto cada 22 días en lugar de hacerlo cada 32 días. En ambos casos, las ganancias finales de peso superaron considerablemente a las del lote 3 (testigo), que fue de solamente $36,4 \mathrm{~kg}$ en los 96 días que duró la experiencia. La diferencia de peso al término del ensayo fue $48,08 \%$ mayor en el Lote 1 con respecto al lote testigo. Los animales experimentales no presentaron reacciones adversas al compuesto administrado.

Las mayores ganancias de peso obtenidas por acción del compuesto ensayado quizás se hayan debido a la interacción entre diversos aminoácidos de las proteínas dietarias y minerales como $\mathrm{Ca}, \mathrm{P}, \mathrm{Fe}$ y $\mathrm{Mg}$, capaces de influir en la absorción intestinal de los nutrientes de la ingesta, como ha sido descripto ${ }^{6}$. Por otra parte, está demostrado que la deficiencia crónica de $\mathrm{Mg}$ es capaz de repercutir sobre la biodisponibilidad de $\mathrm{Ca}$, $\mathrm{Fe}, \mathrm{Cu}, \mathrm{Zn}$ y $\mathrm{Mn}$, interfiriendo en el crecimiento del animal ${ }^{9}$. También debe tenerse en cuenta que numerosos oligoelementos como Fe y Mn son componentes de enzimas antioxidantes, las cuales previenen el daño celular causado por las oxidaciones, por lo cual constituyen nutrientes esenciales en la dieta de los mamíferos ${ }^{4}$.

Las ganancias de peso de los bovinos utilizados en el presente ensayo, de 375 y 440 g/animal día son importantes, habida cuenta que en novillos de hasta dos

Tabla 1. Ganancias de peso registradas en novillos del lote 1 (inyectados cada 22 días).

\begin{tabular}{|c|c|c|c|c|c|c|c|c|}
\hline \multirow{2}{*}{$\mathrm{N}^{\mathrm{o}}$} & \multirow{2}{*}{$\begin{array}{c}\text { 6-2-12 } \\
\text { P inicial }(\mathrm{kg})\end{array}$} & \multicolumn{2}{|c|}{$9-3-12$} & \multicolumn{2}{|c|}{$10-4-12$} & \multicolumn{2}{|c|}{$12-5-12$} & \multirow{2}{*}{$\begin{array}{c}\text { ganancia final } \\
(\mathrm{kg})\end{array}$} \\
\hline & & $\mathrm{P}(\mathrm{kg})$ & $\mathrm{G}(\mathrm{g})$ & $\mathrm{P}(\mathrm{kg})$ & $\mathrm{G}(\mathrm{g})$ & $\mathrm{P}(\mathrm{kg})$ & $\mathrm{G}(\mathrm{g})$ & \\
\hline 1 & 200 & 226 & 812 & 240 & 800 & 253 & 406 & 53 \\
\hline 2 & 209 & 211 & 62 & 230 & 633 & 246 & 500 & 37 \\
\hline 3 & 192 & 229 & 1100 & 249 & 666 & 264 & 469 & 72 \\
\hline 4 & 197 & 209 & 375 & 230 & 700 & 242 & 375 & 45 \\
\hline 5 & 193 & 220 & 843 & 236 & 533 & 249 & 406 & 56 \\
\hline 6 & 186 & 213 & 843 & 237 & 800 & 254 & 531 & 68 \\
\hline 7 & 184 & 205 & 656 & 228 & 766 & 244 & 500 & 60 \\
\hline 8 & 183 & 192 & 281 & 212 & 666 & 226 & 437 & 43 \\
\hline 9 & 171 & 189 & 562 & 204 & 500 & 218 & 437 & 47 \\
\hline 10 & 163 & 182 & 593 & 210 & 933 & 221 & 343 & 58 \\
\hline $\bar{x}$ & 187,8 & 207,6 & 612,7 & 227,6 & 699,7 & 241,7 & 440,4 & 53,9 \\
\hline
\end{tabular}

$\overline{\mathrm{X}}$ : promedio, P: peso vivo, G: ganancia diaria de peso entre pesajes. 
Tabla 2. Ganancias de peso registradas en novillos del lote 2 (inyectados cada 32 días).

\begin{tabular}{ccccccccc}
\hline \multirow{2}{*}{$\mathrm{N}^{\mathbf{0}}$} & $\begin{array}{c}6-2-12 \\
\mathrm{P} \text { inicial }(\mathrm{kg})\end{array}$ & \multicolumn{2}{c}{$9-3-12$} & \multicolumn{2}{c}{$10-4-12$} & \multicolumn{2}{c}{$12-5-12$} & $\begin{array}{c}\text { ganancia final } \\
(\mathrm{kg})\end{array}$ \\
\cline { 2 - 7 } 1 & 200 & 215 & 468 & murió & - & - & - & - \\
2 & 204 & 205 & 31 & 227 & 733 & 236 & 281 & 32 \\
3 & 196 & 221 & 781 & 240 & 633 & 251 & 344 & 55 \\
4 & 194 & 198 & 125 & 220 & 733 & 232 & 375 & 38 \\
5 & 189 & 204 & 468 & 222 & 600 & 236 & 438 & 47 \\
6 & 187 & 200 & 406 & 218 & 600 & 228 & 313 & 41 \\
7 & 184 & 195 & 343 & 215 & 666 & 227 & 375 & 43 \\
8 & 172 & 187 & 468 & 201 & 466 & 212 & 344 & 40 \\
9 & 167 & 181 & 437 & 203 & 733 & 218 & 469 & 51 \\
10 & 160 & 186 & 812 & 202 & 533 & 216 & 438 & 56 \\
$\overline{\mathbf{X}}$ & 183,7 & 197,4 & 430,1 & 216,4 & 633,0 & 228,4 & 375,2 & 44,8 \\
\hline
\end{tabular}

$\overline{\mathrm{X}}$ : promedio, P: peso vivo, G: ganancia diaria de peso entre pesajes.

Tabla 3. Ganancias de peso registradas en novillos del lote 3 (testigos).

\begin{tabular}{ccccccccc}
\hline \multirow{2}{*}{$\mathrm{N}^{\mathbf{2}}$} & $\begin{array}{c}6-2-12 \\
\mathrm{P} \text { inicial }(\mathrm{kg})\end{array}$ & \multicolumn{2}{c}{$9-3-12$} & \multicolumn{2}{c}{$10-4-12$} & \multicolumn{2}{c}{$12-5-12$} & \multirow{2}{*}{$\begin{array}{c}\text { ganancia final } \\
(\mathrm{kg})\end{array}$} \\
\hline 1 & 200 & 210 & 312 & 228 & 600 & 236 & 250 & 36 \\
2 & 200 & 222 & 687 & 230 & 266 & 239 & 281 & 39 \\
3 & 195 & 203 & 250 & 217 & 466 & 226 & 281 & 31 \\
4 & 191 & 194 & 93 & 204 & 333 & 212 & 250 & 21 \\
5 & 187 & 187 & 0 & 201 & 466 & 211 & 312 & 24 \\
6 & 185 & 210 & 781 & 223 & 433 & 229 & 188 & 44 \\
7 & 183 & 186 & 93 & 200 & 466 & 210 & 312 & 27 \\
8 & 180 & 205 & 781 & 226 & 700 & 234 & 250 & 54 \\
9 & 173 & 196 & 718 & 213 & 566 & 225 & 375 & 52 \\
10 & 171 & 181 & 312 & 196 & 500 & 207 & 344 & 36 \\
$\overline{\mathrm{X}}$ & 186,5 & 199,4 & 402,7 & 213,8 & 479,6 & 222,9 & 284,3 & 36,4 \\
\hline
\end{tabular}

$\overline{\mathrm{X}}$ : promedio, P: peso vivo, G: ganancia diaria de peso entre pesajes.

años de edad sobre pasturas naturales, resulta imposible generar ganancias de peso de 500 gramos/animal/ día en cualquier época del año ${ }^{7}$. Se admite que los ritmos de crecimiento superiores a $500 \mathrm{~g} / \mathrm{animal} / \mathrm{día}$ solamente se conseguirían con la administración de suplementos energético-proteicos de alta calidad ${ }^{8}$.

En terneros de destete precoz, formulaciones conteniendo pellets de semilla de algodón lograron ganancias de peso mayores de $500 \mathrm{~g} / \mathrm{animal}_{\mathrm{d}} \mathrm{dí}^{1}$. Suplementando novillos media sangre cebú con semilla de algodón, las ganancias diarias por cabeza resultaron de solamente $292 \mathrm{~g}$ en animales experimentales y $51 \mathrm{~g}$ en testigos ${ }^{2}$. Vacas de invernada cruza cebú suplementadas con pulpa fresca de citrus revelaron ganancias de peso de 492 versus $304 \mathrm{~g} /$ animal/día (primer año) y 352 $\mathrm{g} / \mathrm{animal} / \mathrm{día}$ versus pérdida de peso en controles (segundo año) ${ }^{3}$.

Atento a tales antecedentes, surge como conclusión que el compuesto investigado fue altamente efectivo para generar mayores ganancias de peso en novillos de cría mantenidos sobres pasturas naturales en las condiciones propias del nordeste argentino, resultando más ventajoso inyectarlo cada 22 en lugar de 32 días.
Agradecimientos. A la empresa Maahsa (Molino Asunceno Alberto Heilbrunn S.A., Asunción, Paraguay) por suministrar el compuesto utilizado en la experiencia (Trankaforte ${ }^{\circledR} \times 220 \mathrm{ml}$ ).

\section{REFERENCIAS}

1. Arias AA, Revidatti MA, Capellari A, Slobodzian A. 1997. Destete precoz en el noroeste de Corrientes. Actas de Ciencia y Técnica UNNE (Argentina) 4: 97-100.

2. Coppo JA, Guastalla JW, Scorza SH, Mussart NB. 1997. Composición de carne y grasa de novillos cruza cebú suplementados con semilla de algodón. Veterinaria 6: 2932.

3. Coppo JA, Mussart NB. 2006. Evolución de indicadores nutricionales en vacas de invernada suplementadas con residuos cítricos. Med Vet 87: 3-6.

4. Earle KE. 2001. Nutrientes antioxidantes: su papel en una dieta sana. Selecc Vet 9: 375-379.

5. Mufarrege D. 1993. Distribución estacional de nutrientes minerales para el ganado en pastizales del nordeste argentino. Boletín Anual 1993 del INTA Mercedes (Corrientes, Argentina), p. 102-107. 
6. Pérez-Llamas F, Garaulet M, Martínez JA, Marín JF, Larqué E, Zamora S. 2001. Influence of dietary protein type and iron source on the absorption of amino acids and minerals. J Physiol Biochem 57: 321-328.

7. Pérez-Valega E, Rividdi E, Kaenel R, Maidana R. 2002. Diferencias en la terminación a corral entre terneros machos castrados y enteros. Anales $23^{\circ}$ Sesión Comunic Cientif Univ Nac Nordeste (Corrientes, Argentina), p. 27.

8. Peruchena CO. 1992. Nutrición de bovinos sobre pastizales de baja calidad de la región NEA. Anales XII Sesión Comunic Cientif Fac Cs Vet UNNE (Corrientes, Argentina), p. 1-16.
9. Planells E, Sánchez-Morito N, Montellano MA, Aranda P, Llopis J. 2000. Effect of magnesium deficiency on enterocyte $\mathrm{Ca}, \mathrm{Fe}, \mathrm{Cu}, \mathrm{Zn}, \mathrm{Mn}$ and Se content. J Physiol Biochem 56: 217-222.

10. Underwood EJ, Suttle NF. 1999. The mineral nutrition of livestock, $4^{\text {th }}$ ed., CAB International, Edinburgh (UK), 463 p. 